\title{
The MEDEA FAR-EAST Study: Conceptual framework, methods and first findings of a multicenter cross-sectional observational study
}

Sophia Hoschar ${ }^{1,6+}$, Jiangqi Pan ${ }^{2+}$, Zhen Wang ${ }^{2}$, Xiaoyan Fang ${ }^{1,7}$, Xian'e Tang ${ }^{2}$, Weiqi Shi ${ }^{2}$, Rongxiang $\mathrm{Tu}^{2}$, Peng Xi ${ }^{2}$, Wenliang Che ${ }^{3}$, Hongbao Wang ${ }^{4}$, Yawei Li ${ }^{5}$, Kurt Fritzsche ${ }^{6}$, Xuebo $\mathrm{Liu}^{2+}$, Karl-Heinz Ladwig ${ }^{1,7^{*+}}$ and Wenlin Ma ${ }^{2 \dagger}$

\begin{abstract}
Background: The substantial increase in cardiovascular diseases (CVD) in China over the last three decades warrants comprehensive preventive primary and secondary strategies. Prolonged prehospital delay (PHD) has been identified as a substantial barrier to timely therapeutic interventions for acute myocardial infarction (AMI). Despite worldwide efforts to decrease the patient's decision-making time, minimal change has been achieved so far. Here, we aim to describe the conceptual framework and methods and outline key data of the MEDEA FAR-EAST Study, which aimed to elucidate in-depth barriers contributing to delay in Chinese AMI-patients.

Methods: Data sources of this multicenter cross-sectional observational study are a standardized bedside interview, a self-administered tailored questionnaire tool and the patient chart. PHD was defined as the main outcome and triangulated at bedside. Standard operation procedures ensured uniform data collection by trained study personnel. The study was ethically approved by Tongji-Hospital and applied to all participating hospitals.

Results: Among 379 consecutively screened patients, 296 (78.1\%) fulfilled eligibility criteria. A total of 241 (81.4\%) AMIpatients were male and 55 (18.6\%) female. Mean age was 62.9 years. Prehospital delay time was assessed for 294 (99.3\%) patients. Overall median PHD was 151 min with no significant sex difference. Symptom mismatch was present in 200 (69. 7\%) patients and 106 (39.0\%) patients did not attribute their symptoms to cardiac origin. A total of 33 (12.4\%) patients suffered from depression, 31 (11.7\%) from anxiety and 141 (53.2\%) patients employed denial as their major coping style.

Conclusion: This is the first study on prehospital delay with emphasis on psychological variables in Chinese AMI-patients. A comprehensive assessment tool to measure clinical and psychological factors was successfully implemented. Sociodemographic key data proved a good fit into preexisting Chinese literature. Potential barriers including cardiac denial and symptom-mismatch were assessed for the first time in Chinese AMI-patients. The pretested selection of instruments allows future in depth investigations into barriers to delay of Chinese AMI-patients and enables inter-cultural comparisons.
\end{abstract}

Keywords: Acute myocardial infarction, Prehospital delay, Cross-sectional observational, Multicenter study, China,

\footnotetext{
* Correspondence: ladwig@helmholtz-muenchen.de

† Sophia Hoschar, Jiang Qi Pan, Xue Bo Liu, Karl-Heinz Ladwig and Wen Lin

Ma contributed equally to this work.

${ }^{1}$ Institute of Epidemiology II, Mental Health Research Unit, Helmholtz

Zentrum München, German Research Center for Environmental Health

(GmbH), Ingolstädter Landstr 1, 85764 Neuherberg, Germany

${ }^{7}$ Department of Psychosomatic Medicine and Psychotherapy, Technical

University Munich, Munich, Germany

Full list of author information is available at the end of the article
}

(c) The Author(s). 2019 Open Access This article is distributed under the terms of the Creative Commons Attribution 4.0 International License (http://creativecommons.org/licenses/by/4.0/), which permits unrestricted use, distribution, and reproduction in any medium, provided you give appropriate credit to the original author(s) and the source, provide a link to the Creative Commons license, and indicate if changes were made. The Creative Commons Public Domain Dedication waiver (http://creativecommons.org/publicdomain/zero/1.0/) applies to the data made available in this article, unless otherwise stated. 


\section{Background}

In China, the burden of cardiovascular disease (CVD) is substantially increasing and is now the leading cause of death [1], accounting for a 1-year incidence of two million acute myocardial infarction (AMI) patients in China in the year 2011 [2]. AMI was responsible for 64.25 deaths per 100.000 inhabitants in 2014 [3].

Therapeutic interventions of AMI are highly time-dependent [4]. Despite recommendations by international guidelines to arrive at the hospital door within $2 \mathrm{~h}$ upon symptom-onset, prehospital delay (PHD) remains a global obstacle to timely treatment $[4,5]$. A recent worldwide review on prehospital delay which included studies from Southeast Asia and China has estimated median prehospital delay time to range between 1.6-12.9 $\mathrm{h}$ [6]. The major component of PHD is patient-related delay [7], which is widely acknowledged to account for about $75 \%$ of overall prehospital delay [8]. Up to now, a total of eight internationally recognized clinical studies on delay time during AMI have been performed in China [916] (see Table 1). Compared to estimates of median delay times in high-income countries [17], median prehospital delay times in these Chinese investigations ranged in a relatively favorable time window of 130 to $150 \mathrm{~min}[9,10,12,13,15]$, nevertheless showing that still more than half of Chinese MI-patients fail to reach emergency facilities within the recommended time window of $120 \mathrm{~min}$.

Substantial efforts have been undertaken to reduce patient-related prehospital delay in numerous populations and secondary based prevention campaigns [18], yet, the results were mostly disappointing [19]. Recently, positive effects on prehospital delay could be demonstrated in interventions that specifically addressed subjective risk-perception in patient decision-making [20, 21], providing a promising concept for future preventive efforts. Unfortunately, the major bulk of delay research in both the western world and in China (see Table 1) is currently restricted to data assessments on sociodemographic and symptom-related variables which do not target those "psychological barriers" increasingly acknowledged as major drivers [22] in the final decision to dispatch emergency medicine services (EMS) [23].

At AMI-onset, several factors such as slow symptom-onset, intermittent symptoms, symptom vagueness [24] and experiencing symptoms which do not match one's expectations of AMI-symptoms [25] or are attributed to causes other than the heart can act as barriers to recognizing symptoms in a timely manner. Additionally, the decision process to seek immediate medical help may be compromised by low perceived personal risk or by health attitudes like cardiac denial [26] even when symptoms are acknowledged as cardiac in origin [27].
Little is known about the impact of depression, anxiety and other psychosocial conditions on the delay process. It is yet not unlikely that depressed patients might delay due to a lack of motivation and energy to seek help [28] whereas anxiety may sharpen the patients self-perceived risk and thus render them more capable of making decisions to get immediate help [29]. Though generalized anxiety may decrease delay time [29], insufficient knowledge of the time dependent nature of treatment as well as being afraid of causing a "false alarm" or "not wanting to bother the physicians" might keep patients from seeking professional help [30].

The MEDEA Study in Munich (Germany, 2007-2012) was developed to overcome shortcomings in delay research focusing on symptom patterns only, and to broaden the horizons of this research. It provided a conceptual framework and subsequent data assessment to identify barriers to help-seeking behavior during an acute infarction situation. The multicenter cross-sectional MEDEA FAR-EAST Study was designed to replicate this study, with its major objective being the application of a holistic approach in addressing patient-related delay by examining somatic, clinical, health-psychology related concepts and influential affective factors on prehospital delay in Chinese AMI-patients. The preselection of instruments was guided by (a) theoretical framework, (b) validated instruments in the Chinese language and (c) and the applicability within the particular Chinese cultural background. The aim of this paper is to present the framework, methods and descriptive study data on prehospital delay times as well as factors related to patient characteristics and symptom-onset.

\section{Methods}

\section{Study design}

The main inclusion criterion was hospitalization with an acute myocardial infarction (AMI), confirmed by typical symptoms at onset, and elevated cardiac biomarkers (troponin I or troponin $\mathrm{T}$ ) as well as corresponding ECG-diagnosis. No restrictions were made regarding age and sex. Exclusion criteria were an out-of-hospital cardiac arrest as well as cognitive impairment and language barrier.

\section{Study setting}

Shanghai is the largest city in China with a total population of 24.2 million people and an average population density of 3816 people per $\mathrm{km}^{2}$ in its urban areas [31]. Across the nation, Shanghai has the largest percentage of aging population (> 65 years) accounting for $18.1 \%$ compared to the national average of $10.1 \%$ [32]. Furthermore, life expectancy among Shanghai residents is among the highest in China with a mean age of 83.2 


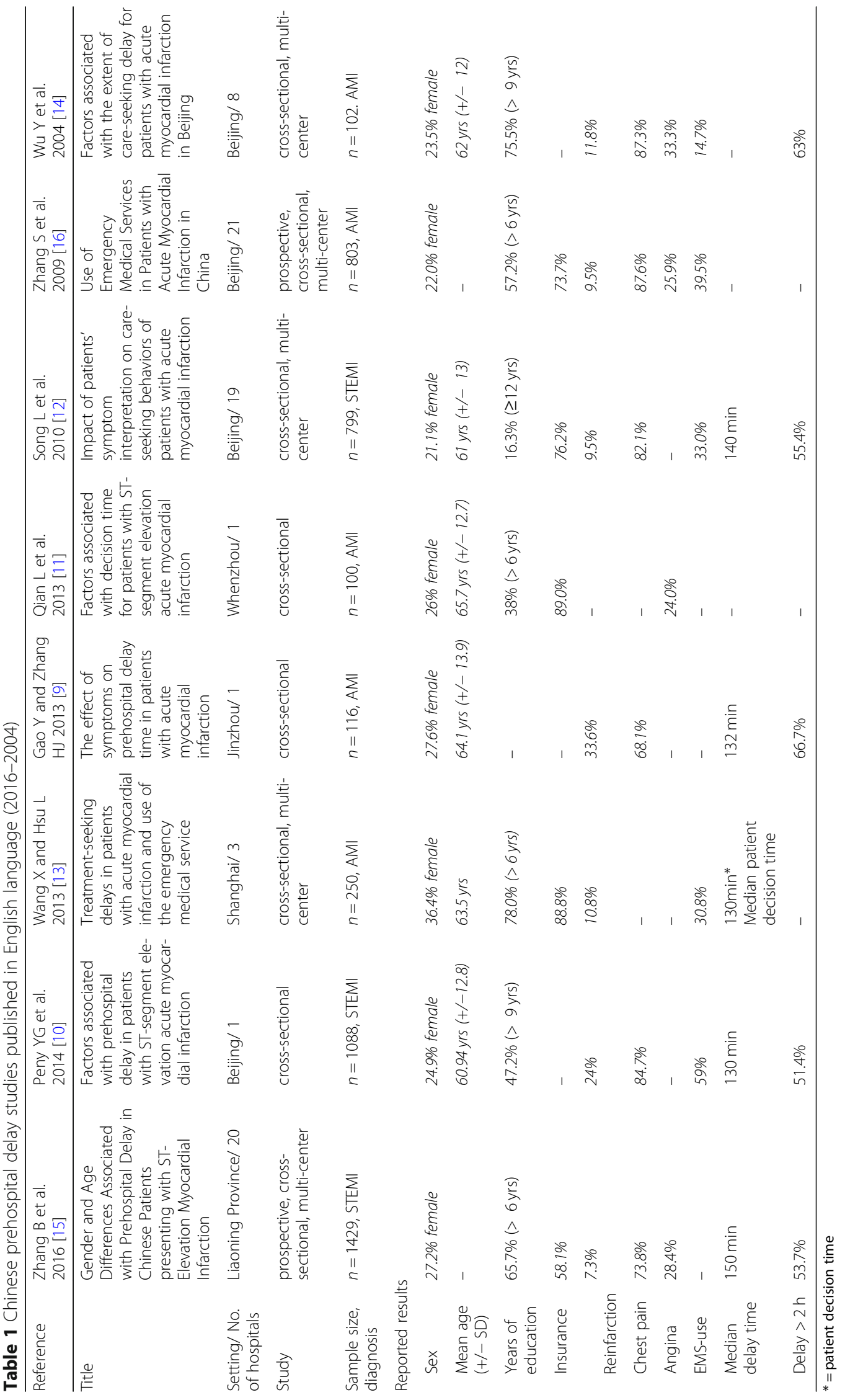


years in 2016 [31]. Combined with decreasing birth rates, this confronts Shanghai with an overall aging population. In China, $90 \%$ of inhabitants have basic health insurance [30]. This health insurance, however, varies in its coverage depending on population groups and registration area, and patients have to pay variable shares. Family physicians present only a negligible 5.6\% of all Chinese physicians [33]. Instead, the majority of doctor visits (90\% in 2012) take place in outpatient departments of public hospitals which results in overcrowding, long waiting times and short patient-doctor encounters [34]. Medical insurance covers all expenses for emergency treatments in public hospitals, nevertheless, non-life-threatening emergency-department visits and hospitalizations require the patient to pay a deposit [35]. Ambulance services are only used among a third of AMI-patients [13], possibly due to costs, low efficacy or missing awareness of emergency medical services. Insurance covers a variable proportion of the fee that is charged for ambulance use [36].

\section{Clinical setting and organization}

The patient sample was recruited from four cardiology departments in Shanghai, all providing acute coronary care units. After preselection of instruments (by S. Hoschar et al.), a Chinese version of the study protocol was presented to the Ethics Commission of the Tongji-University affiliated Tongji-Hospital (by W. Ma). The Commission approved the study on 16th of March 2016 (伦审-KYSB-2016-74). The ethics approval applied to all participating centers. Recruitment started in Tongji-Hospital in Mid-April together with Yangpu-Hospital and 455 People's Hospital. By end of July, recruitment was expanded to Tenth-Hospital. Recruitment was ended in Mid-January 2017.

Patient inclusion and data collection were performed within two days after hospitalization (SD: +/- 1.87 days, $n=86$ ). On average, between one to $2 \mathrm{~h}$ were spent by trained personnel conducting the interview and assisting patients with completing the questionnaire. Regular newsletters informed all study-affiliated members of the study's progress and developments. The study personnel received training prior to their participation and were closely monitored during the data acquisition process in order to avoid reporting bias. Standard operating procedures (SOP) were implemented to ensure the training of new members and these methods were kept consistent for all participating hospitals.

\section{Data sources}

The data collection procedure was divided into three parts. First, a bedside interview was conducted with trained study personnel. After this, a self-administered questionnaire was handed to the patient for self-assessment. Lastly, basic epidemiological and medical information were collected from the hospitals' patient charts. The patients were followed up at bedside or via telephone calls for any missing or incoherent answers.

\section{Information from the interview}

Assessment of prehospital delay times Prehospital delay time was the primary outcome defined as the time interval between symptom-onset and arrival at the hospital door, measured in minutes. Symptom-onset was clearly defined as symptoms that worsened or stayed continuous without decreasing over time. Nevertheless, defining symptom-onset remained a challenge (for example, patients often had difficulties to differentiate between prodromal symptoms and intermittent acute onset). The onset-time was triangulated by trained personnel in the interview, using events from the patient's daily routine to help them establish the chronology of symptom-onset. Patients were asked to give a broad estimate of the time of symptom-onset, which was then further specified by placing it in relation to times of regular activities, meals, sleeping habits and other routines. This technique has previously been developed and tested by Moser et al., who found that this technique enabled patients who did not initially remember onset-time to successfully recall it [37]. The hospital registration receipt (挂号单, Guàhàodān) was used as the hospital arrival time, either directly or through the hospital information center. Additionally, an effort was made to distinguish decision from transportation, by coding time of decision to seek help as a secondary outcome. Prompting the time of decision to seek help provided patients with an additional anchor item and followed the recommendations of Mackay et al. to collect at least two components of prehospital delay [38].

Health related behavior At bedside, comprehensive data on sociodemographic and health-related behaviors were assessed (physical activity, burden of work, smoking). Health attitudes and frequency of doctor consultation prior to AMI helped to portray patient's overall approach to health. Angina pectoris six months prior to AMI was assessed following the Rose Angina Questionnaire [39] which allowed the evaluation of any prodromal chest pain (PCP), chest pain of unknown origin (unexplained PCP), possible angina or definite angina.

Symptom presentation at AMI-onset The acute onset of MI was a central part of the interview to outline details of symptom presentation. The duration, intensity and character (e.g. intermittent, increasing over time) of chest pain and/or other cardiac symptoms were documented. Patient interpretation of the onset-symptoms 
was measured by the items patient expectation and symptom attribution.

Behavioral responses to $\mathrm{AMI}$ and context variables The Response of Symptoms Questionnaire [40] was used to obtain information factors contributing to delay in the following domains: (1) the context in which AMI-symptoms appeared (at home, during work etc.); (2) to address with whom the patient was and what they were doing when the signs and symptoms occurred; (3) the responses of witnesses to the patient's symptoms; (4) the behavioral responses to symptoms (e.g. wait and see; trying to relax; calling the emergency system); (5) the affective response to the symptoms. Subjective rating of helplessness, fear of death and fear before seeking help was assessed in single-item instruments. Mode of transportation was coded in the interview as self-transportation, transportation by others and transportation via ambulance.

\section{Information from the self-administered questionnaire}

The self-administered questionnaire assessed variable psychometric variables including psychological characteristics, personality concepts as well as AMI-related knowledge. Except for the instrument measuring AMI-related knowledge, all psychometric instruments used were standardized instruments, summarized in detail in Table 2.

We used two scales to measure affective disorders. Depression was measured using the Major Depression Inventory (MDI), a 10-domain instrument able to generate an ICD-10 diagnosis. Following the suggestion of Bech et al. [64], a cut-off point ( $>25$ ) was chosen when using the MDI as a rating scale. Anxiety was measured using a validated translation of the Generalized Anxiety Disorder Scale (GAD-7) [42], where scores of above or equal to 10 highlights anxious patients.

Denial regarding cardiac illness was measured in the 8-item Cardiac Denial of Impact Score (CDIS) [55]. A score of $\geq 25$ indicates cardiac denial.

Stress was measured by two items, a) the INTER-HEART Stress Scale (IHS) [43], a 3-item instrument measuring stress in financial, family and work-related context. Furthermore, the short version of the perceived stress scale [45] depicts a global measure of stress in 4 items. The somatic symptom burden was captured by the somatic symptom scale (SSS-8) [44] which comprises 8 items to detect somatic, anxiety and depression-related symptoms.

Health locus of control was measured using the Multidimensional Health Locus of Control Scale (MHLC). It consists of 12 items and was initially developed by Wallston et al. [52] and features 3 domains.

The social support was measured by the Chinese 10-item Social Support Rating Scale (SSRS) [46]. It measures social support in 3 domains, namely subjective, objective and usage of social support.

Well-being was measured by the WHO-5 [53], a 5 -item instrument developed by the WHO to measure happiness, energy, motivation and interest in daily life.

Type-D personality was measured using the Type-D Scale 14 (DS-14) which is divided into two subscales with 7 items each, measuring social inhibition and negative affectivity [58]. Type-A personality was measured using the Framingham Type A behavior score (FRAS), consisting of 10 items to measure behavior indicative of Type A [59].

Resilience was measured in a short 5 -item version (RS-5) developed from the original version of the RS-14 [65]. This tool measures the domains of personal competence and acceptance of self and life.

Knowledge of AMI-symptoms and appropriate actions to be taken when experiencing those symptoms was measured in the questionnaire in two subscales. In the interview, sources of AMI-knowledge were identified, including physician, media, heart association and friends/ acquaintances as possible sources.

As can be further seen in Table 2, the majority of psychometric instruments applied in the present investigation had been validated and applied in Chinese language and were published in Chinese research papers prior to our investigation [46-51, 60-63]. However, the Major Depression Inventory (MDI) [41], the INTER-HEART Stress Scale (IHS-Scale) [43], the short version of the Resilience Scale (RS-4) [57] and the Cardiac Denial of Impact Scale (CDIS) [55] were not available in Chinese. Therefore, these instruments were translated following the recommended translation guidelines of back-and-forth translation by the WHO [66]. Previous to enrollment, these four instruments were pretested in 20 patients to ensure that patients were able to understand all items.

\section{Information from the hospital chart}

Detail of the infarction diagnosis, elevation of cardiac biomarkers and the number of days spent in CCU, complications throughout the stay as well as therapy of the MI were documented in the hospital chart. The patient chart additionally examined if the patient was previously transferred from a hospital not capable of treating the patient for AMI.

\section{Data entry}

The study coordinator entered the data in an Excel sheet. Checklists were created in order to monitor progress of data collection.

\section{Sample size calculation}

It was estimated that $30 \%$ of participants would reach the hospital within $<120 \mathrm{~min}$. With the assumption of a $5 \%$ error we estimated a sample size of 310 patients to 


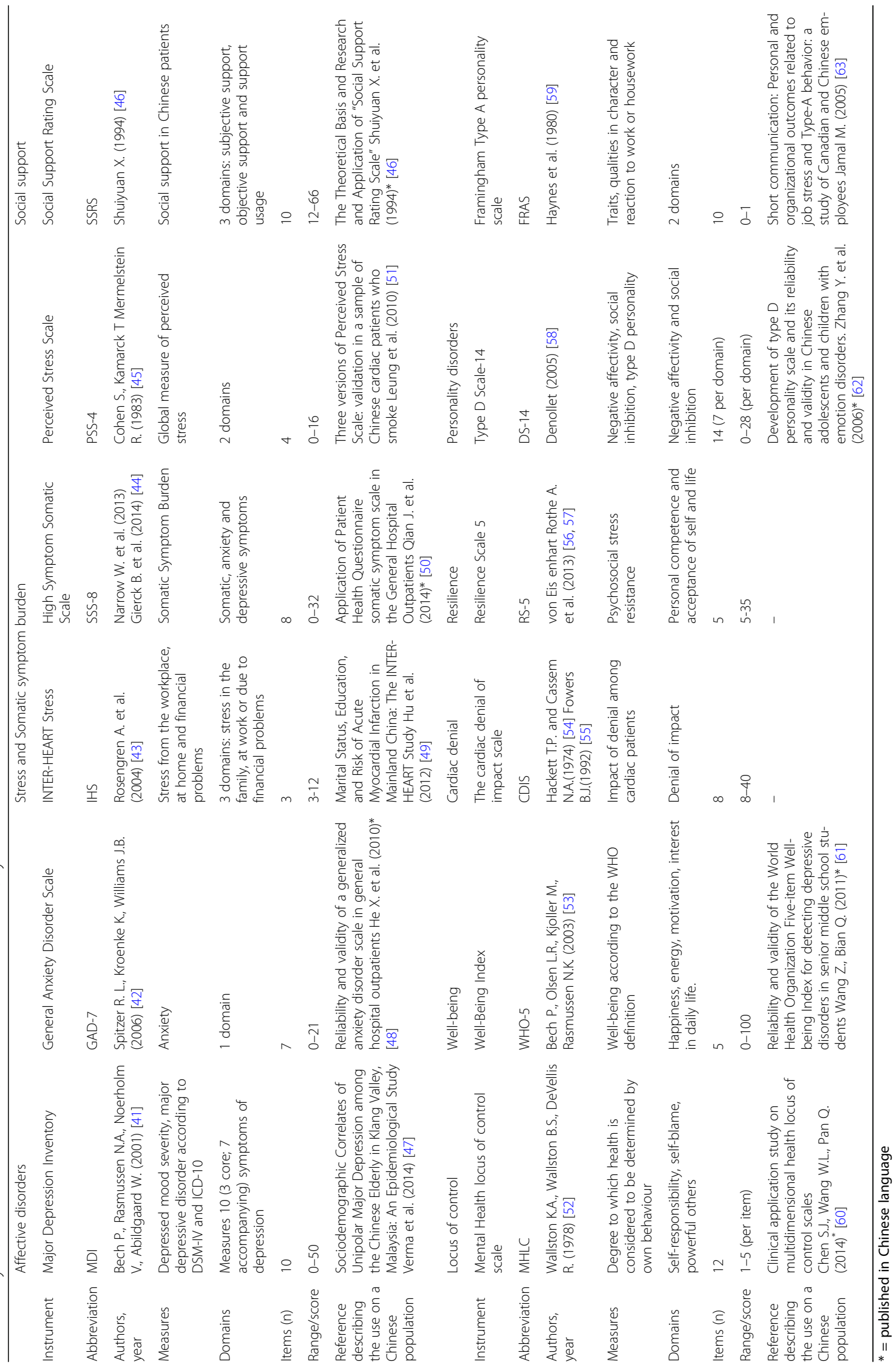


ensure a power of 0.80 in proving a clinically relevant odds ratio of 2.0.

\section{Data analysis}

Differences between continuous variables were assessed using Mann Whitney Test. All statistical analysis was run in IBM SPSS Statistics version 20 (SPSS Inc., Chicago). The distribution of delay was available as a continuous variable in minutes and heavily left-skewed, thus reporting medians delay times. Dichotomized measures of symptom expectation ( $\leq 3$ vs $>3$ on 5 point Likert scale) and symptom attribution (cardiac vs. non-cardiac) were used. The significance level $\alpha$ was set at .05. Differences in median PHD were assessed using the non-parametric Wilcoxon test. The analysis and description in this paper follow the STROBE guidelines for cross-sectional studies [67].

\section{Results}

\section{Sample size and dropout-analysis}

A total of 379 patients were considered eligible from mid-April 2016 to mid-January 2017, of which 83 (21.9\%) were excluded (see Fig. 1). Causes for exclusion were refusal $(n=25,30.1 \%)$ language barrier or/and cognitive impairment $(n=21,25.3 \%)$, as well as other reasons such as unconfirmed diagnosis $(n=5,6.0 \%)$ or missing data $(n=22,26.5 \%)$. One patient $(1.2 \%)$ was in a too critical condition to be interviewed and three patients $(3.6 \%)$ were already in hospital when they experienced AMI. For six patients (7.2\%), the reason for exclusion remained undocumented. In the present analysis, two patients had missing values of onset time, so that prehospital delay could not be determined. A dropout-analysis showed that older age was a significant factor of dropout, with patients dropping out being a mean of 69.3 years old (compared to a mean of 62.9 years in our study, $p<0.001$ ). Comparison of included and excluded patients showed no significant differences in gender $(p=0.46)$.

\section{Patient characteristics}

A total of 296 patients participated in the MEDEA FAR-EAST Study and completed the bedside interview. Among them, 241 (81.4\%) were male and 55 (18.6\%) female (see Table 3 ). The mean age of the study population was 62.9 years (median age: 63.0 years, IQR: 14 years, SD: 13. 2 years) following a near to normal distribution (see Fig. 2). The mean age of men was 61.3 years and differed significantly from women's mean age of 69.9 years $(p<0.001)$. The mean age, the proportion of male patients and prehospital delay did not vary significantly between the four recruitment hospitals $(p=0.17$; $p=0.42, p=0.88)$. Among the study population, 29 (9.8\%) had attended six years of elementary school and

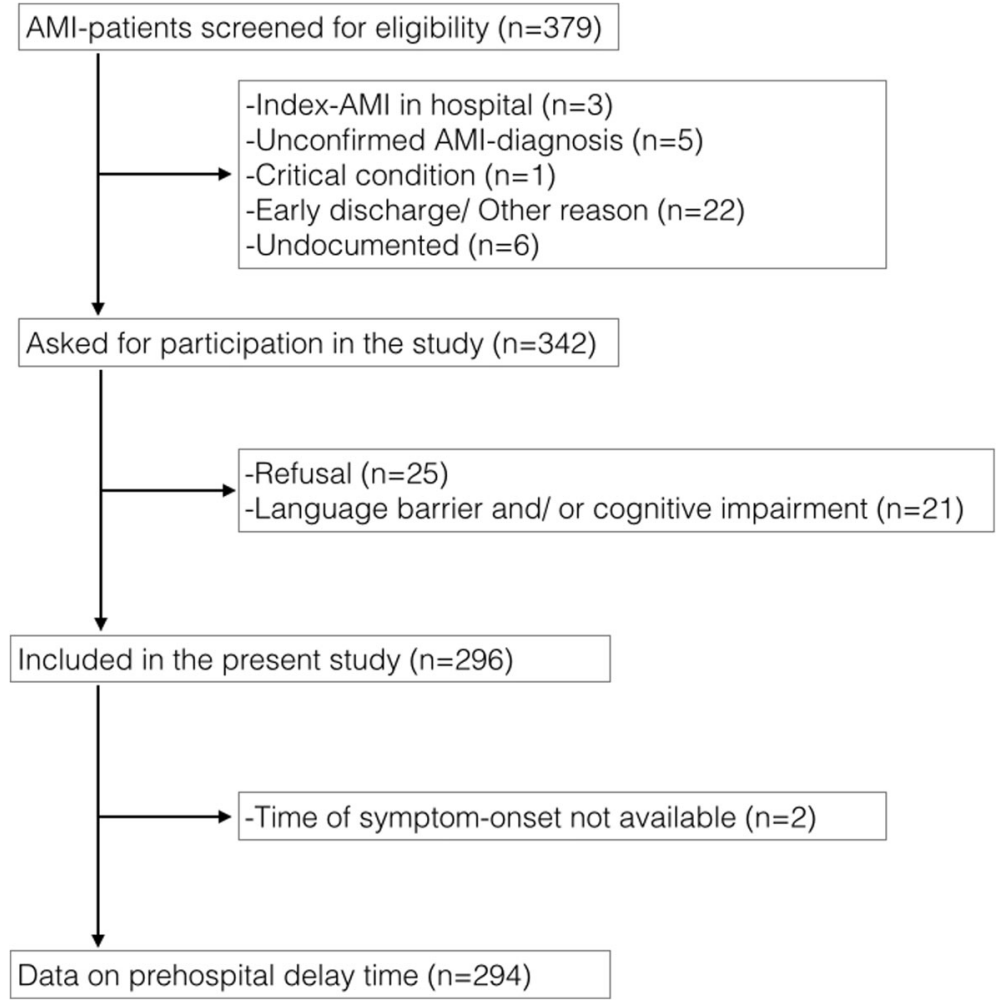

Fig. 1 Flow-diagram for inclusion and exclusion 
114 (38.5\%) an additional three years of junior-high school. 93 (31.4\%) patients attained a senior-high school degree and 46 (15.5\%) had a university degree.

A total of 14 patients (4.7\%) had completed no education at all. $236(80.5 \%)$ out of 293 patients were medically insured. A total of $24(8.1 \%)$ patients had previously experienced AMI. A total of 178 (60.1\%) patients experienced prodromal chest pain (PCP) prior to AMI, which could be classified as angina pectoris in 76 (25.7\%) cases. Among our patient sample, 31 (11.7\%) patients suffered from anxiety, 33 (12.4\%) from depression, and 141 (53.2\%) from cardiac denial during the 6 months prior to AMI. The response rate for all three questionnaires was at least $89.5 \%$.

\section{Factors surrounding symptom-onset}

Upon symptom-onset of AMI, 121 (40.9\%) of patients experienced a 'classical' onset with chest pain and radiating pain into left arm, right arm, neck/jaw, shoulders or epigastric region (see Table 4). Chest pain without radiation was experienced by 138 (46.6\%) patients. 37 (12.5\%) patients stated that they did not experience any form of chest pain. $166(61.0 \%)$ patients attributed their symptoms to cardiac origin. 200 (69.7\%) patients felt that their symptom didn't match their previous expectation of a heart attack. A majority of the patients $(176$ of $294,59.9 \%)$ were driven to the hospital by either private or public transportation (see Table 4). $67(22.8 \%)$ patients reached the hospital via ambulance. The remaining $51(17.3 \%)$ patients stated that they walked or drove to the hospital themselves.

\section{Prehospital delay}

Prehospital delay was available for 294 patients. The overall median prehospital delay time in the patient sample was $150.5 \mathrm{~min}$, with $152 \mathrm{~min}$ (IQR: 70, 495) for men and $143 \mathrm{~min}$ for woman (IQR: 80,662). This difference was not significant ( $p=0.88$ ) (see Fig. 3). A total of 132 (44.9\%) patients arrived at the hospital door within a favorable time window of less than 120 min (see Fig. 3). 48 (16.3\%) patients delayed within a critical time window of 120 to 239 min. In 25 (8.5\%) patients, delay times between 240 and 359 min were documented. A total of $89(30.3 \%)$ patients exhibited a detrimental delay of $360 \mathrm{~min}(6 \mathrm{~h})$ and more.

\section{Discussion}

Despite an often imperative and severe pain pattern in the face of an acute myocardial infarction, and despite increasing knowledge in the population of the need to access therapeutic help as quick as possible, inadequate delay times of AMI patients remain an universal problem with a reported average median delay time of about 204 min among 23 studies worldwide [6]. In contrast to this finding, the MEDEA FAR EAST Study including 296 AMI-patients revealed a clinically-relevant median
Table 3 Sociodemographic, clinical and psychological characteristics of Chinese AMI-patients

\begin{tabular}{|c|c|c|}
\hline & Percentage (n) & total $(n)$ \\
\hline \multicolumn{3}{|l|}{ Baseline patient characteristics } \\
\hline \multicolumn{3}{|l|}{ Sex } \\
\hline Male & $81.4 \%(241)$ & 296 \\
\hline Female & $18.6 \%(55)$ & \\
\hline \multicolumn{3}{|l|}{ Age } \\
\hline Older age ( $\geq 60$ years) & $60.8 \%(180)$ & 296 \\
\hline Younger age ( $<60$ years) & $39.2 \%(116)$ & \\
\hline \multicolumn{3}{|l|}{ Years of education } \\
\hline 6 years (elementary school) & $9.8 \%(29)$ & 296 \\
\hline 9 years (middle school) & $38.5 \%(114)$ & \\
\hline 12 years (senior high-school) & $31.4 \%(93)$ & \\
\hline Over 12 years (university degree) & $15.5 \%(46)$ & \\
\hline Less than 6 years or none & $4.7 \%(14)$ & \\
\hline \multicolumn{3}{|l|}{ Medical insurance } \\
\hline Insured & $80.5 \%(236)$ & 293 \\
\hline Not-insured & $19.5 \%(57)$ & \\
\hline \multicolumn{3}{|l|}{ Clinical patient characteristics } \\
\hline \multicolumn{3}{|l|}{ AMI-history } \\
\hline First infarction & $91.9 \%(272)$ & 296 \\
\hline Reinfarction & $8.1 \%(24)$ & \\
\hline \multicolumn{3}{|l|}{ Prodromal chest pain } \\
\hline Chest pain & $60.1 \%(178)$ & 296 \\
\hline No chest pain & $39.9 \%(118)$ & \\
\hline \multicolumn{3}{|l|}{ Psychological patients characteristics } \\
\hline Anxiety (Score $\geq 10$ ) & $11.7 \%(31)$ & 265 \\
\hline Depression (Score > 25) & $12.4 \%(33)$ & 267 \\
\hline Cardiac denial (Score $\geq 25$ ) & $53.2 \%(141)$ & 265 \\
\hline
\end{tabular}

prehospital delay of $151 \mathrm{~min}$, with more than half of the patients delaying over $2 \mathrm{~h}$. This finding is in line with previous investigations on median delay times in Chinese AMI-patients with a substantially lower time window ranging between 130 and $150 \mathrm{~min}$ over time [10, 12, 13, $15,68]$.

The study has been performed in Shanghai - one of the world's biggest cities. Nevertheless, our descriptive analysis demonstrates that the population under investigation in the MEDEA FAR-EAST Study has comparable characteristics to related investigations in China. This is particularly true concerning mean age $[10,12,14,16]$, gender distribution [12, 14], education [10] and insurance rate $[12,16]$.

The MEDEA FAR-EAST Study is, to the best of our knowledge, the first clinical study in the context of cardiac emergency facilities in China to comprehensively assess clinical, psychological and health-behavior related 


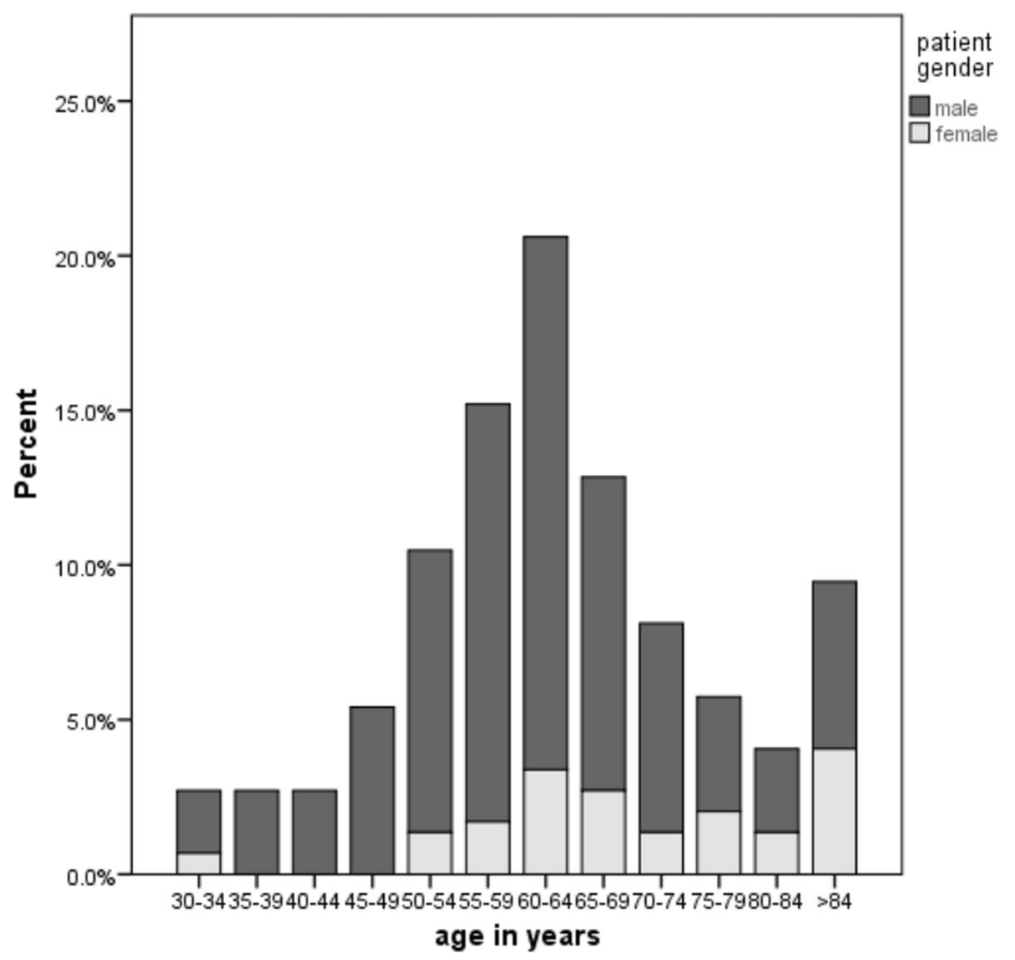

Fig. 2 Patient age divided into 5-year intervals, split by gender, $n=296$ AMl-patients

Table 4 Factors surrounding symptom-onset in Chinese AMIpatients

\begin{tabular}{|c|c|c|}
\hline & Percentage (n) & total $(n)$ \\
\hline \multicolumn{3}{|l|}{ Onset of acute myocardial infarction } \\
\hline \multicolumn{3}{|l|}{ In the acute situation } \\
\hline Chest pain and radiation & $40.9 \%(121)$ & 296 \\
\hline Only chest pain & $46.6 \%(138)$ & \\
\hline No chest pain & $12.5 \%(37)$ & \\
\hline \multicolumn{3}{|l|}{ Symptom appraisal at symptom-onset } \\
\hline \multicolumn{3}{|l|}{ Symptom attribution } \\
\hline Cardiac (> 3) & $61.0 \%(166)$ & 272 \\
\hline Non-cardiac $(\leq 3)$ & $39.0 \%(106)$ & \\
\hline \multicolumn{3}{|l|}{ Symptom expectation } \\
\hline As expected (>3) & $30.3 \%(87)$ & 287 \\
\hline Not as expected $(\leq 3)$ & $69.7 \%(200)$ & \\
\hline \multicolumn{3}{|l|}{ Context variables of symptom-onset } \\
\hline \multicolumn{3}{|l|}{ Transport } \\
\hline Self-transported (walking/ driving) & $17.3 \%(51)$ & 294 \\
\hline Driven by others (private/ public) & $59.9 \%(176)$ & \\
\hline Via ambulance & $22.8 \%(67)$ & \\
\hline
\end{tabular}

features in a homogeneous population of acute cardiac patients. In order to gain a deeper understanding of patients' decision processes, it is also one of the first studies worldwide to assess depression, anxiety and self-perceived stress, but also the patient's level of resilience and attitude towards the medical system. It not only screens for typical but also atypical symptoms and complaints, and furthermore assesses factors like symptom expectation and knowledge.

\section{Patient characteristics}

Our results showed that the majority of patients were male, 60 years of age or older, and had attended school for at least six years. A majority of patients were experiencing acute myocardial infarction for the first time. About $12 \%$ of them suffered from anxiety and/or depression while cardiac denial was more common, with approximately half of the patients exhibiting cardiac denial in the prodromal phase. To date, the prevalence of depression, anxiety and cardiac denial prior to AMI has not been investigated in China. In the German counterpart study, prevalence of anxiety and cardiac denial among STEMI-patients was $11 \%$ and $42 \%$, which correlates well with our figures $[26,29]$. In a study examining depression among elderly Chinese in Malaysia, the prevalence of depression using the MDI was found to be $10.7 \%$ among 150 participants [47]. A prevalence of $12.4 \%$ in our patient sample corresponds well to that 


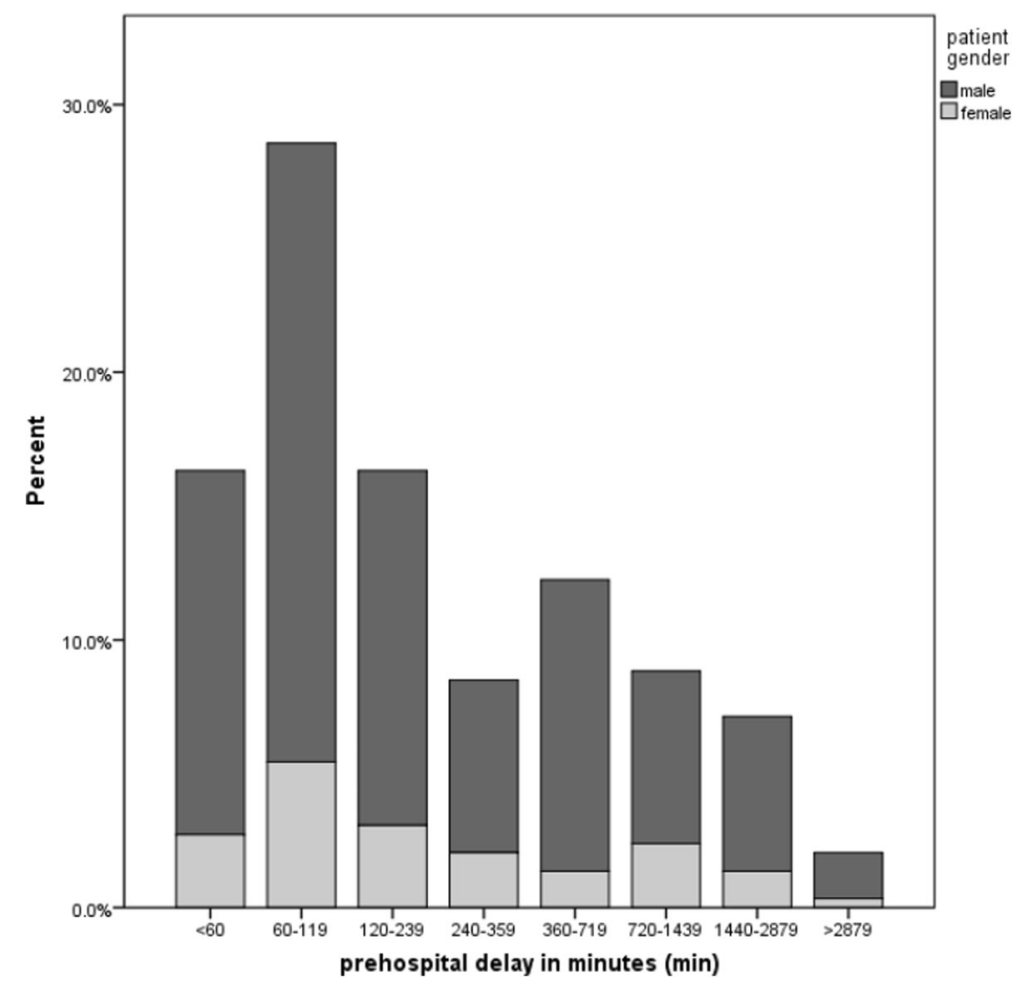

Fig. 3 Prehospital delay (PHD) in intervals, split by gender, $n=294$ AMI-patients

figure. The validation study of the GAD-7 scale in 600 Chinese outpatient patients found a prevalence of $4.7 \%$. Our figure was higher, possibly explained by a higher perceived risk of MI among cardiovascular patients which has been shown to be associated with anxiety [29].

\section{Factors surrounding symptom-onset}

In the acute situation, the vast majority of patients experienced chest pain which corresponds to figures previously reported in China [10]. "It is noteworthy that, in the current investigation, a total of 39\% of patients attributed their symptoms to non-cardiac origin and around $70 \%$ of patients stated that they experienced symptoms other than they had expected. In previous studies in China, the prevalence of patients attributing their symptoms to non-cardiac origin was around $42-45 \%$, [12, 14] which corresponds with our data, while symptom-mismatch among Chinese AMI-patients was reported to be much lower in the literature, with a figure around $31 \%$ [12]". As a response to these symptoms most patients were driven to the hospital or walked/ drove themselves. $22.6 \%$ of patients used the ambulance. A slightly higher proportion of around 31\% was reported in a prehospital delay study set in Shanghai [13], which might be explained by the higher insurance rate reported in that study. The consistency of our results with Chinese literature can be seen as a measure of the validity of the data collected on AMI-patients in this investigation.

\section{Strengths and limitations}

The strength of this study is that efforts were made to reduce recall bias by conducting a bedside interview within a narrow time-frame upon hospitalization, while additionally using an approved technique for triangulation of onset-time. Yet recall bias might still exist, as data collection was retrospective. Due to the cross-sectional study design, causal attributions cannot be made. Furthermore, despite our best efforts, consecutive inclusion is likely but cannot be fully guaranteed. The study was conducted in an urban setting in China which may prevent conclusions for rural areas and countries other than China. Furthermore, prehospital delay puts patients at risk of sudden cardiac arrest, the major cause of out-of-hospital death in the prehospital phase [69]. These patients were not included in our investigation. Furthermore, four instruments (MDI-scale, IHS-scale, RS-5-scale and CDI-scale) were not available in Chinese and had to be translated and pre-tested.

\section{Conclusions}

Substantial progress has been made in minimizing transportation and door-to-needle time. However, patient 
delay remains a major unresolved concern of public health. In order to develop effective prevention campaigns for the future, the patient-related barriers to seek medical help must be better understood. Clarifying psychological and bio-behavioral factors as well as intercultural comparisons will provide key evidence for developing new approaches in prevention.

Symptom perception and miscellaneous psychological and behavioral factors may contribute equally, in a complex interaction, to inner barriers of the patient's decision-making process. The present investigation is the first study in a Chinese population to capture comprehensive data applying theory-guided standardized instruments, allowing focus on the particularly vulnerable decision process. The prevalence of potential contributors to prehospital delay, such as symptom interpretation, and psychological barriers such as depression and cardiac denial were measured. In particular, symptom mismatch and cardiac denial were present in more than half of the patients, and we aim to conduct further analysis in the future to examine their association with prehospital delay.

Furthermore, barriers in treatment seeking behavior have been shown to vary by region and culture [70]. It is of note that this investigation strictly follows the protocol previously applied in the German MEDEA Study, enabling us, in the future, to conduct in-depth analyses of possible psychological and cultural differences in behavior and perception of threat cues during a critical and highly stressful event. Of note, in the German MEDEA-study, overall median delay time of all 619 study participants was $203 \mathrm{~min}$ and was $151 \mathrm{~min}$ in the MEDEA FAR-EAST Study - a first difference to be further clarified in future comparisons of delay between German and Chinese AMI-patients.

\section{Abbreviations \\ AMI : Acute myocardial infarction; CCU: Coronary Care Unit; CDIS: Cardiac Denial of Impact Scale; CVD: Cardiovascular disease; DS-14: Type-D Personality Scale; ECG: Electrocardiogram; EMS: Emergency Medical Services; FRAS: Framingham Type A behavior score; GAD-7: Generalized Anxiety Disorder Scale with 7 items; ICD-10: International Classification of Diseases; IHS: Interheart stress scale; IQR: Interquartile Range; MDI: Major depression inventory; MHLC: Multidimensional health locus of control scale; NSTEMI: Non-ST-elevated myocardial infarction; PCP: Prodromal chest pain; RS-4: Resilience Scale with 4 items; SD: Standard deviation; SOP: Standard operating procedures; SSRS: Social Support Rating Scale; SSS-8: Somatic symptom scale with 8 items; STEMI: ST-elevated myocardial infarction; WHO: World Health Organization; WHO-5: Well-being scale by the WHO}

\section{Acknowledgements}

We would like to acknowledge the work of the following MEDEA FAR-EAST interviewers: Zhaoyu Zhang, Wei Sun, Yuxing Wu, Jingin, Zhangyuan Gu, Haili Gan, Jiaojiao Hou, Dingfeng Liu, Yuqing Wang, Kexiong, Siyuan Hu, Ziwen Zhu, Tiansheng Zheng and Yinglei Zhang. We furthermore thank Dr. Wu Heng for advising us on the final instruments. We thank all enrolled patients for their participation in our study.

\section{Funding}

This work was supported by the Science and Technology Committee Foundation of Shanghai, PR China (16411965500, 16511102802) to Prof. Ma
Wenlin and by the German Heart Foundation to Prof. Karl-Heinz Ladwig. The funding was used to cover printing fees and to pay the study personnel.

\section{Availability of data and materials}

The dataset that was used and analyzed during the current study is available from the corresponding author on reasonable request.

\section{Authors' contributions}

SH served as the study coordinator from April 2016 to October 2016, and performed data collection and data entry, prepared the final dataset, analyzed and interpreted the data and drafted the manuscript. JQP served as the study coordinator from October 2016 to January 2017 and was responsible for data collection, data entry and drafting the manuscript. ZW participated in data collection and data entry. XYF contributed to the study design. XT, WQS, RXT and PX carried out data collection at Tongji-Hospital and organizational tasks. WLC coordinated the study in Tenth- Hospital and critically revised the final manuscript. WHB coordinated the study in YangpuHospital and critically revised the manuscript. YWL coordinated the study in 455-Hospital and critically revised the manuscript. KF contributed to designing and setting up the study. XBL coordinated the study in Tongji-Hospital and critically revised the manuscript. KHL was a study investigator and participated in study conception, study design, data analysis and drafting the manuscript. WLM served as a study investigator and was responsible for recruiting team members, data collection, supervising the data-entry and submitting the application for ethical approval. All authors critically revised the script and approved the final manuscript and furthermore agreed to be held accountable for all aspects of the work.

\section{Ethics approval and consent to participate}

The Ethics Commission of Tongji-University affiliated Tongji-Hospital approved the study on 16th of March 2016 (Reference Number: 伦审-KYSB2016-74). This approval is applicable for all participating centers (Tongji-Hospital, Yangpu-Hospital, Tenth-Hospital and 455 Hospital). All patients with suspected AMI were asked for their permission to be interviewed and had to give written consent. Study participation was voluntary, patients were informed about the procedures of the study and they were assured that refusal would not affect their treatment. When written consent was not possible due to somatic weakness (e.g. poor eyesight), oral consent had to be given and was documented.

\section{Consent for publication}

Not applicable.

\section{Competing interests}

The authors declare that they have no competing interests.

\section{Publisher's Note}

Springer Nature remains neutral with regard to jurisdictional claims in published maps and institutional affiliations.

\section{Author details}

${ }^{1}$ Institute of Epidemiology II, Mental Health Research Unit, Helmholtz Zentrum München, German Research Center for Environmental Health $(\mathrm{GmbH})$, Ingolstädter Landstr 1, 85764 Neuherberg, Germany. ${ }^{2}$ Department of Cardiology, Tongji-Hospital, Tongji-University, Shanghai, People's Republic of China. ${ }^{3}$ Department of Cardiology, Tenth-Hospital, Tongji-University, Shanghai, People's Republic of China. ${ }^{4}$ Department of Cardiology, Yangpu-Hospital, Tongji-University, Shanghai, People's Republic of China. ${ }^{5}$ Department of Cardiology, 455-Hospital, Tongji-University, Shanghai, People's Republic of China. ${ }^{6}$ Department of Psychosomatic Medicine and Psychotherapy, Medical Center- University of Freiburg, Faculty of Medicine, Freiburg, Germany. ${ }^{7}$ Department of Psychosomatic Medicine and Psychotherapy, Technical University Munich, Munich, Germany.

Received: 4 October 2018 Accepted: 14 March 2019

Published online: 02 May 2019

\section{References}

1. Yang G, Wang Y, Zeng Y, Gao GF, Liang X, Zhou M, et al. Rapid health transition in China, 1990-2010: findings from the global burden of disease study 2010. Lancet. 2013;381:1987-2015. 
2. Li H, Ge J. Cardiovascular diseases in China: current status and future perspectives. IJC Heart Vasc. 2015;6:25-31.

3. Chang J, Liu X, Sun Y. Mortality due to acute myocardial infarction in China from 1987 to 2014: secular trends and age-period-cohort effects. Int J Cardiol. 2017;227:229-38.

4. O'Gara PT, Kushner FG, Ascheim DD, Casey DE Jr, Chung MK, de Lemos JA et al. 2013 ACCF/AHA guideline for the management of ST-elevation myocardial infarction: a report of the American College of Cardiology Foundation/American Heart Association task force on practice guidelines. J Am Coll Cardiol. 2013;61:e78-140.

5. Spencer FA, Montalescot G, Fox KAA, Goodman SG, Granger CB, Goldberg $\mathrm{RJ}$, et al. Delay to reperfusion in patients with acute myocardial infarction presenting to acute care hospitals: an international perspective. Eur Heart J. 2010;31:1328-36.

6. Wechkunanukul K, Grantham H, Clark RA. Global review of delay time in seeking medical care for chest pain: an integrative literature review. Aust Crit Care. 2017;30:13-20.

7. Doggen CJM, Zwerink M, Droste HM, Brouwers PJAM, van Houwelingen GK, van Eenennaam $\mathrm{FL}$, et al. Prehospital paths and hospital arrival time of patients with acute coronary syndrome or stroke, a prospective observational study. BMC Emerg Med. 2016;16(3).

8. $\mathrm{C}-\mathrm{H} R, \mathrm{~A} M, J \mathrm{~K}, \mathrm{~T} H$. Patient delay from onset of chest pain suggesting acute coronary syndrome to hospital admission. Scand Cardiovasc J. 2003; 37:183-6.

9. Gao $Y$, Zhang $H$. The effect of symptoms on prehospital delay time in patients with acute myocardial infarction. J Int Med Res. 2013;41:1724-31.

10. Peng YG, Feng JJ, Guo LF, Li N, Liu WH, Li GJ, et al. Factors associated with prehospital delay in patients with ST-segment elevation acute myocardial infarction in China. Am J Emerg Med. 2014;32:349-55.

11. Qian L, Ji K, Nan J, Lu Q, Zhu Y, Wang L, et al. Factors associated with decision time for patients with STsegment elevation acute myocardial infarction. J Zhejiang Univ Sci B. 2013;14:754-8.

12. Song L, Yan H-B, Yang J-G, Sun Y-H, Hu D-Y. Impact of patients' symptom interpretation on care-seeking behaviors of patients with acute myocardial infarction. Chin Med J (Engl). 2010;123:1840-5.

13. Wang $X$, Hsu LL. Treatment-seeking delays in patients with acute myocardial infarction and use of the emergency medical service. J Int Med Res. 2013;41:231-8.

14. Wu Y, Zhang Y, Li Y, Hong B, Huang C. Factors associated with the extent of care-seeking delay for patients with acute myocardial infarction in Beijing. Chin Med J (Engl). 2004;117:1772-7.

15. Zhang B, Zhang W, Huang R, Zhu H, Liu J, Jiang D, et al. Gender and age differences associated with prehospital delay in Chinese patients presenting with ST-elevation myocardial infarction. J Cardiovasc Nurs. 2016;31:142-50.

16. Zhang S, Hu D, Wang X, Yang J. Use of emergency medical Services in Patients with acute myocardial infarction in China. Clin Cardiol. 2009;32:137-41.

17. Moser DK, Kimble LP, Alberts MJ, Alonzo A, Croft JB, Dracup K, et al. Reducing delay in seeking treatment by patients with acute coronary syndrome and stroke: a scientific statement from the American Heart Association Council on cardiovascular nursing and stroke council. Circulation. 2006;114:168-82.

18. Kainth A, Hewitt A, Sowden A, Duffy S, Pattenden J, Lewin R, et al. Systematic review of interventions to reduce delay in patients with suspected heart attack. Emerg Med J. 2004;21:506-8.

19. Mooney M, McKee G, Fealy G, O'Brien F, O'Donnell S, Moser D. A review of interventions aimed at reducing pre-hospital delay time in acute coronary syndrome: what has worked and why? Eur J Cardiovasc Nurs. 2012;11:445-53.

20. Mooney M, McKee G, Fealy G, O' Brien F, O'Donnell S, Moser D. A Randomized Controlled Trial to Reduce Prehospital Delay Time in Patients With Acute Coronary Syndrome (ACS). J Emerg Med. 2014;46:495-506.

21. Bray JE, Stub D, Ngu P, Cartledge S, Straney L, Stewart M, et al. Mass media campaigns' influence on prehospital behavior for acute coronary syndromes: an evaluation of the Australian Heart Foundation's warning signs campaign. J Am Heart Assoc. 2015;4:e001927.

22. Dracup K, Moser DK. Beyond sociodemographics: factors influencing the decision to seek treatment for symptoms of acute myocardial infarction. Heart Lung. 1997;26:253-62.

23. Ladwig K-H, Gärtner C, Walz LM, Smenes KR, Ronel J. The inner barrier: how health psychology concepts contribute to the explanation of prehospital delays in acute myocardial infarction: a systematic analysis of the current state of knowledge. Psychother Psychosom Med Psychol. 2009;59:440-5.
24. Nymark C, Mattiasson A-C, Henriksson P, Kiessling A. The turning point: from self-regulative illness behaviour to care-seeking in patients with an acute myocardial infarction. J Clin Nurs. 2009;18:3358-65.

25. Abed MA, Abu Ali RM, Abu Ras MM, Hamdallah FO, Khalil AA, Moser DK. Symptoms of acute myocardial infarction: a correlational study of the discrepancy between patients' expectations and experiences. Int J Nurs Stud. 2015;52:1591-9.

26. Fang $X Y$, Albarqouni L, von Eisenhart Rothe AF, Hoschar S, Ronel J, Ladwig K-H. Is denial a maladaptive coping mechanism which prolongs pre-hospital delay in patients with ST-segment elevation myocardial infarction? J Psychosom Res. 2016:91:68-74

27. Li PW, Yu DS. Predictors of pre-hospital delay in Hong Kong Chinese patients with acute myocardial infarction. Eur J Cardiovasc Nurs. 2018;17:75-84

28. Bunde J, Martin R. Depression and prehospital delay in the context of myocardial infarction. Psychosom Med. 2006;68:51-7.

29. Fang XY, Spieler D, Albarqouni L, Ronel J, Ladwig K-H. Impact of generalized anxiety disorder (GAD) on prehospital delay of acute myocardial infarction patients. Findings from the multicenter MEDEA study. Clin Res Cardiol. 2018; 107:1-8.

30. Albarqouni L, Smenes K, Meinertz T, Schunkert H, Fang X, Ronel J, et al. Patients' knowledge about symptoms and adequate behaviour during acute myocardial infarction and its impact on delay time: findings from the multicentre MEDEA study. Patient Educ Couns. 2016; 99:1845-51.

31. Shanghai Statistical Bureau. Shanghai Statistical Yearbook 2017, vol. 2019. http:// www.statssh.gov.cn/html/sjfb/201801/1001529.html. Accessed 22 Jan 2019

32. Yang F, Gu D, Mitnitski A. Frailty and life satisfaction in Shanghai older adults: the roles of age and social vulnerability. Arch Gerontol Geriatr. 2016; 67:68-73.

33. Wu D, Lam TP. At a Crossroads: Family Medicine Education in China. Acad Med. 2017:92:185-91.

34. Bao Y, Fan G, Zou D, Wang T, Xue D. Patient experience with outpatient encounters at public hospitals in Shanghai: examining different aspects of physician services and implications of overcrowding. PLoS One. 2017;12: e0171684.

35. Pei $\mathrm{W}$, Xiao F. Emergency medicine in China: present and future. World J Emerg Med. 2011;2:245-52.

36. Hung KKC, Cheung CSK, Rainer TH, Graham CA. EMS systems in China. Resuscitation. 2009;80:732-5.

37. Moser DK, McKinley S, Dracup K, Chung ML. Gender differences in reasons patients delay in seeking treatment for acute myocardial infarction symptoms. Patient Educ Couns. 2005;56:45-54.

38. Mackay MH, Ratner PA, Nguyen M, Percy M, Galdas P, Grunau G. Inconsistent measurement of acute coronary syndrome patients' prehospital delay in research: a review of the literature. Eur J Cardiovasc Nurs. 2014;13:483-93.

39. Rose G, McCartney P, Reid DD. Self-administration of a questionnaire on chest pain and intermittent claudication. Br J Prev Soc Med. 1977;31:42-8.

40. Burnett RE, Blumenthal JA, Mark DB, Leimberger JD, Califf RM. Distinguishing between early and late responders to symptoms of acute myocardial infarction. Am J Cardiol. 1995;75:1019-22.

41. Bech P, Rasmussen NA, Olsen LR, Noerholm V, Abildgaard W. The sensitivity and specificity of the major depression inventory, using the present state examination as the index of diagnostic validity. J Affect Disord. 2001;66:159-64.

42. Spitzer RL, Kroenke K, Williams JBW, Löwe B. A Brief Measure for Assessing Generalized Anxiety Disorder. Arch Intern Med. 2006;166(10):1092.

43. Rosengren A, Hawken S, Ônpuu S, Sliwa K, Zubaid M, Almahmeed WA, et al. Association of psychosocial risk factors with risk of acute myocardial infarction in 11119 cases and 13648 controls from 52 countries (the INTERHEART study): case-control study. Lancet. 2004;364:953-62.

44. Gierk B, Kohlmann S, Kroenke K, Spangenberg L, Zenger M, Brähler E, et al. The somatic symptom scale-8 (SSS-8): a brief measure of somatic symptom burden. JAMA Intern Med. 2014;174:399-407.

45. Cohen S, Kamarck T, Mermelstein R. A global measure of perceived stress. J Health Soc Behav. 1983;24:385-96.

46. Shuiyuan X. Theoretical Background Study and Application of Social Support Rate Scale (in Chinese). J Clin Psychiatry. 1994;02:98-100.

47. Verma RK, Min TH, Chakravarthy S, Barua A, Kar N. Sociodemographic correlates of unipolar major depression among the Chinese elderly in Klang Valley, Malaysia: an epidemiological study. Sci World J. 2014; https://doi.org/ 10.1155/2014/812712. 
48. He X, Li C, Q J. Reliability and validity of a generalized anxiety disorder scale in general hospital outpatients. 22.4 (2010): 200-203. 2010;22:200-3.

49. Hu B, Li W, Wang X, Liu L, Teo K, Yusuf S. Marital Status, Education, and Risk of Acute Myocardial Infarction in Mainland China: The INTER-HEART Study. J Epidemiol. 2012;22(2):123-9.

50. Qian J, Ren Z, Yu D, He X, Li C. Application of patient health questionnaire somatic symptom scale in the general hospital outpatients. Chin Mental Health J. 2014;28:173-8.

51. Leung DYP, Lam T-h, Chan SSC. Three versions of Perceived Stress Scale: validation in a sample of Chinese cardiac patients who smoke. BMC Public Health. 2010;10(1)

52. Wallston KA, Wallston BS, DeVellis R. Development of the multidimensiona health locus of control (MHLC) scales. Health Educ Behav. 1978;6:160-70.

53. Bech $P$, Olsen $L R$, Kjoller M, Rasmussen NK. Measuring well-being rather than the absence of distress symptoms: a comparison of the SF-36 mental health subscale and the WHO-five well-being scale. Int J Methods Psychiatr Res. 2003;12:85-91.

54. Hackett TP, Cassem NH. Development of a quantitative rating scale to assess denial. J Psychosom Res. 1974;18(2):93-100.

55. Fowers BJ. The cardiac denial of impact scale: a brief, self-report research measure. J Psychosom Res. 1992;36:469-75.

56. von Eisenhart Rothe A, Zenger M, Lacruz ME, Emeny R, Baumert J, Haefner $S$, et al. Validation and development of a shorter version of the resilience scale RS-11: results from the population-based KORA-age study. BMC Psychology. 2013;1.

57. von Eisenhart Rothe A, Zenger M, Lacruz ME, Emeny R, Baumert J, Haefner $S$, et al. Validation and development of a shorter version of the resilience scale RS-11: results from the population-based KORA-age study. BMC Psychol. 2013;1:25

58. Denollet J. DS14: standard assessment of negative affectivity, social inhibition, and type D personality. Psychosom Med. 2005;67:89-97.

59. Haynes S, Feinleib M, Kannel WB. The relationship of psychosocial factors to coronary heart disease in the Framingham study. III. Eight-year incidence of coronary heart disease. Am J Epidemiol. 1980;111:37-58.

60. Chen S, Wang W, Pan Q. Clinical application study on multidimensional health locus of control scales. Chin Nurs Res. 2014;28:1682-4.

61. Wang Z, Bian Q. Reliability and validity of the World Health Organization Five-item Well-being Index for detecting depressive disorders in senior middle school students (in Chinese). Chin Ment Health J. 2011:279-83.

62. Zhang Y, Zhang Y, Zhou S, Li H. Development of type D personality scale and its reliability and validity in Chinese adolescents and children with emotion disorders. Chin J Behav Med Sci. 2006;15:757-9.

63. Jamal M. Personal and organizational outcomes related to job stress and Type-A behavior: a study of Canadian and Chinese employees. Stress and Health. 2005;21(2):129-37.

64. Bech P, Timmerby N, Martiny K, Lunde M, Soendergaard S. Psychometric evaluation of the major depression inventory (MDI) as depression severity scale using the LEAD (longitudinal expert assessment of all data) as index of validity. BMC Psychiatry. 2015;15 https://doi.org/10.1186/s12888-015-0529-3.

65. Wagnild GM, Young HM. Development and psychometric evaluation of the resilience scale. J Nurs Meas. 1993;1:165-78.

66. WHO. Process of translation and adaptation of instruments. WHO. http:// www.who.int/substance_abuse/research_tools/translation/en/. Accessed 13 Apr 2017.

67. von Elm E, Altman DG, Egger M, Pocock SJ, Gøtzsche PC, Vandenbroucke JP. The strengthening the reporting of observational studies in epidemiology (STROBE) statement: guidelines for reporting observational studies. J Clin Epidemiol. 2008;61:344-9.

68. Hu D, Yang J, Pi L, Sun Y. Prehospital Delay After Acute ST-SegmentElevation Myocardial Infarction in Beijing, China. In: CIRCULATION. LIPPINCOTT WILLIAMS \& WILKINS 530 WALNUT ST, PHILADELPHIA, PA 19106-3621 USA; 2010. p. E57.

69. Karam N, Bataille S, Marijon E, Giovanetti O, Tafflet M, Savary D, et al. Identifying Patients at Risk for Pre- Hospital Sudden Cardiac Arrest at the Early Phase of Myocardial Infarction: The e-MUST Study. Circulation. 2016; 134:2074-83 CIRCULATIONAHA.116.022954.

70. McKinley S, Dracup K, Moser DK, Ball C, Yamasaki K, Kim CJ, et al. International comparison of factors associated with delay in presentation for AMl treatment. Eur J Cardiovasc Nurs. 2004;3:225-30.

Ready to submit your research? Choose BMC and benefit from:

- fast, convenient online submission

- thorough peer review by experienced researchers in your field

- rapid publication on acceptance

- support for research data, including large and complex data types

- gold Open Access which fosters wider collaboration and increased citations

- maximum visibility for your research: over $100 \mathrm{M}$ website views per year

At $\mathrm{BMC}$, research is always in progress.

Learn more biomedcentral.com/submissions 